\title{
Study on Excellence of Academic Discipline for World-class Universities and the Gap analysis for Chinese Top-level Universities
}

\author{
On the basis of ESI World Ranking
}

\author{
Yun Yuan* \\ Department of Development and Planning \\ Northwestern Polytechnical University \\ Xi'an, P.R. China \\ yuanyun@nwpu.edu.cn \\ *Corresponding author
}

\author{
Xizhe Zhi \\ Department of Development and Planning \\ Northwestern Polytechnical University \\ Xi'an, P.R. China \\ zhixz@nwpu.edu.cn
}

\begin{abstract}
This paper addressed Essential Science Indicators (ESI) as a key performance indicator for universities and focused on analyzing the excellence of academic disciplines from ESI perspective, mainly among world-class universities and Chinese 985-project universities. It illustrated the typical discipline excellence of world-class universities in terms of the quantity of disciplines ranking top $1 \%$ in the world ESI, with new insights on the average level of the quantity. Accordingly, it also disclosed the commonalities of world-class universities in keeping a good balance between basic science and applied science. The gap of discipline excellence existing between world-class universities and Chinese universities was investigated. In general, this paper provides a measurable and quantifiable benchmark means for universities to evaluate academic discipline performance, especially meaningful for Chinese universities on their ways to build world-class universities.
\end{abstract}

Keywords-Essential Science Indicators; world-class university; 985-project university; discipline ranking; performance-driven development

\section{INTRODUCTION}

With deepening of education reform in China and the government's more concerns to gain value for money led to universities, Chinese universities start to focus more on better quality and performance, rather than simply pursuing for larger scales and more investment. Significant efforts are taken in finding and applying appropriate means for goal setting and performance evaluation. Performance Indicators and Evaluation Systems have become very important to measure efficiency and effectiveness of the development. This trend has been imposed on the education service, and higher education is no exception amid great expectations, though there are significant challenges in measuring performance in higher education [1].

Essential Science Indicators (ESI) can determine the influential individuals, institutions, papers, publications and countries in their field of study. The science performance statistics and science trends data are compiled and based on journal article publication counts and citation data from Thomson Scientific Database. ESI has been taken as a very important indicator to evaluate university academic discipline development in China [2]. In the 3-rd round University Academic Discipline Evaluation in China, ESI was taken as one of the performance indicator as the first time by Ministry of Education of China.

In order to get deeper insights on how universities perform based on ESI this key performance indicator, the paper starts with a study on world ESI rankings of academic disciplines of different universities. There are 22 academic disciplines categorized by ESI in total. Institutions or universities can be ranked by their paper citations accumulated during the last ten years, either for individual discipline or for all 22 ESI disciplines as a whole. In general, once paper citations of a certain discipline is selected into the top $1 \%$ of the world, this particular discipline is regarded as a discipline ranking top $1 \%$ in the world ESI [3].

World-class universities and non-world-class universities are used to classify universities for the study here. Universities which are studied in this paper are mainly world-class universities. Despite of different definitions of world-class universities, they share common characteristics in faculty, students, resource, research and management to a large extent [4]. In the paper, world-class are taken as both world first-class universities which ranking world top 100, and world wellknown universities which ranking top 101 200 universities to serve the purpose of the study.

In China, 39 985-project universities generally represent the best of universities in China in many aspects. It is essential for Chinese universities to understand where they are today and what the gaps are compared with world-class universities. ESI aids for university benchmarking and performance evaluation, and therefore plays more important roles for Chinese universities to become world-class universities.

\section{ANALYSIS}

\section{A. World first-class universities}

In order to get better understandings of the correlation between disciplines ranking in the world ESI and academic performance of universities, a set of world first-class universities are taken as samples for the investigation. 90 
universities are selected from top 100 universities listed by Times Higher Education World University Rankings (THEWUR) 2014-2015.

The discipline rankings of these 90 universities have been examined carefully and the quantity of discipline which ranking top $1 \%$ in the world ESI in each university is shown in Fig. 1.

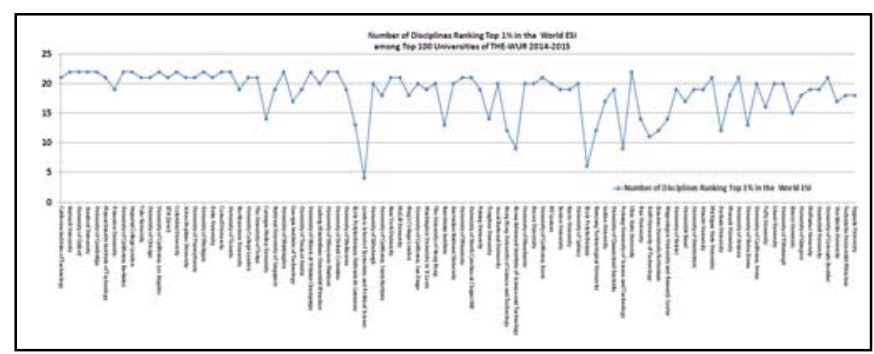

FIGURE I. QUANTITY OF DISCIPLINES RANKING TOP 1\% IN THE WORLD ESI FOR WORLD FIRST-CLASS UNIVERSITIES (90 of TOP 100) (Source: THE-WUR 2014-2015 \& ESI database @2014-10)

According to Fig. 2, further observations include (1) each of $90 \%$ universities has at least 13 disciplines ranking as top $1 \%$ in the world ESI; (2) each of $80 \%$ universities has at least 17 disciplines ranking as top $1 \%$ in the world ESI; (3) the average quantity of disciplines ranking top $1 \%$ in the world ESI, is about 18.5 for a world first-class university as analyzed.

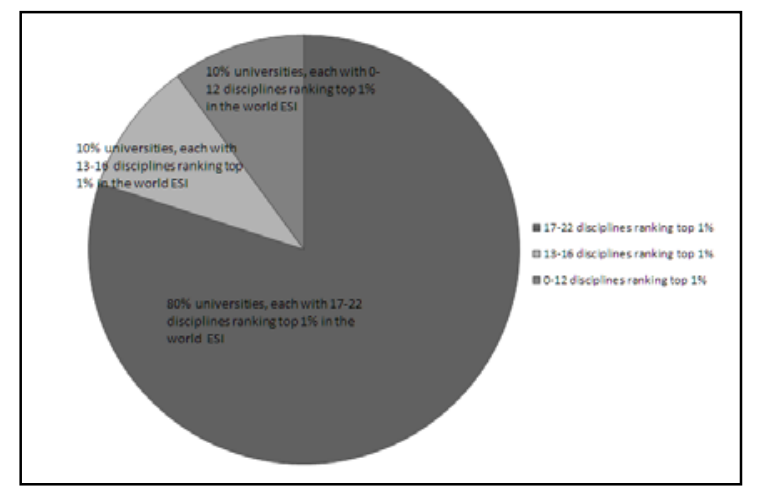

FIGURE II. DISCIPLINES EXCELLENCE ANALYSIS IN TERMS OF THE WORLD ESI RANKING FOR 90 WORLD FIRST-CLASS UNIVERSITIES (Source: THE-WUR 2014-2015 \& ESI database @2014-10)

Taking a closer look at the top 50 universities ranked by THE-WUR 2014-2015, the new findings include (1) each of $90 \%$ universities has at least 15 disciplines ranking as top $1 \%$ in the world ESI; (2) each of $70 \%$ universities has at least 20 disciplines ranking as top $1 \%$ in the world ESI; (3) the average number of disciplines ranking top $1 \%$ in the world ESI, is 19.8 for each of top 50 universities studied, as shown in Fig. 3.

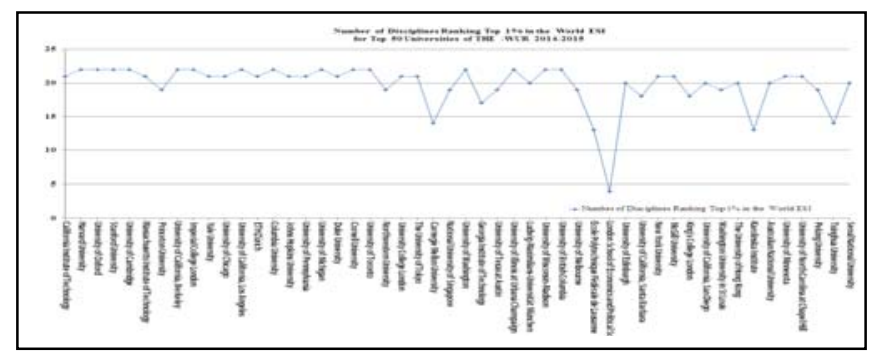

FIGURE III. Q QUANTITY OF DISCIPLINES RANKING TOP $1 \%$ IN THE WORLD ESI FOR TOP 50 UNIVERSITIES (Source: THE-WUR 2014-2015 \& ESI database @,2014-10)

In order to explore how a world first-class university balances its various disciplines, all disciplines which are ranking top $1 \%$ in the world ESI in the university are ranked by paper citations of each within this university. 8 world first-class universities are randomly selected from top 100 universities in table 1. According to it, Caltech has 21 disciplines ranking top $1 \%$ in the world ESI. Within Caltech, these 21 disciplines are ranked based on paper citations of each discipline during the last ten years. It is found that discipline of space science and physics ranks higher than the other disciplines and therefore these 2 disciplines hold the top positions in Caltech.

TABLE I. RANKINGS OF PAPER CITATIONS FOR EACH DISCIPLINE IN SOME WORLD FIRST-CLASS UNIVERSITIES (SOURCE: THE-WUR 2014-2015 \& ESI DATABASE@2014-10)

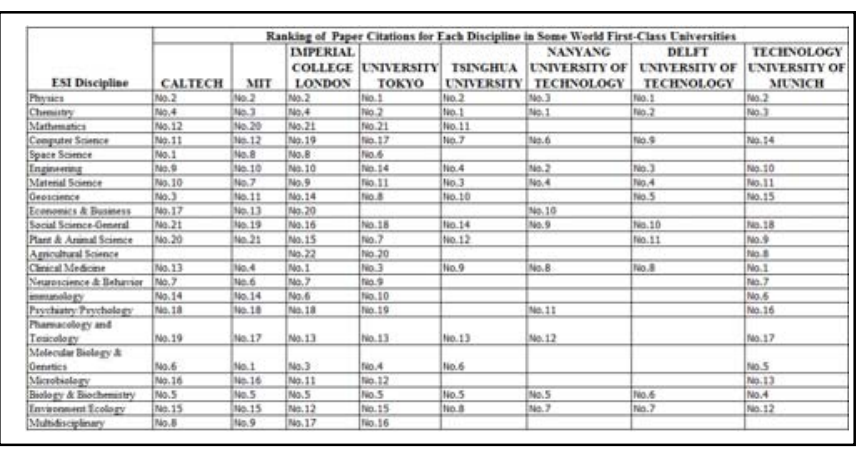

B. World well-known universities

To extend the study into a wider scope, another set of universities is chosen from top 101 200 universities of THEWUR 2014-2015, cited as world well-known universities in this paper. Similarly, discipline excellence, in terms of quantities of disciplines ranking top $1 \%$ in the world ESI, is investigated in Fig. 4.

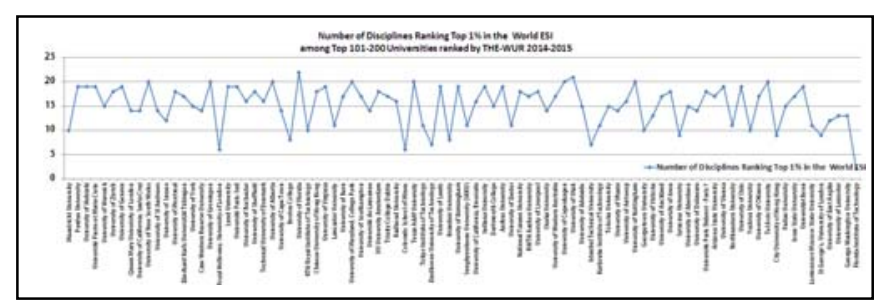

FIGURE IV. QUANTITY OF DISCIPLINES RANKING TOP $1 \%$ IN THE WORLD ESI FOR WORLD WELL-KNOWN UNIVERSITIES $(90$ of TOP 101 200) (Source: THE-WUR 2014-2015 \& ESI database @2014-10) 
Fig. 5 further illustrates that (1) each of $75 \%$ universities has at least 13 disciplines ranking top 1\% in the world ESI; (2) each of $\sim 48 \%$ universities has at least 17 disciplines ranking top $1 \%$ in the world ESI; (3) The average number of disciplines ranking top $1 \%$ in the world ESI is 15 , for each of world wellknown universities studied.

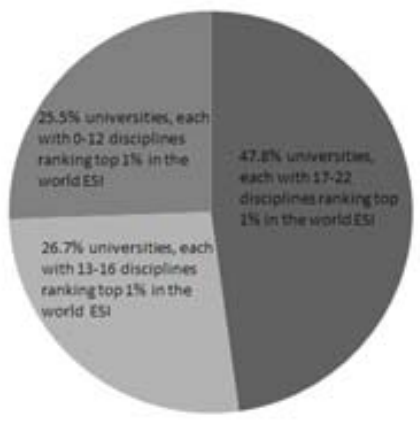

-17,22 dexwinesimaing top 16

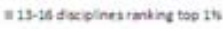

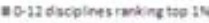

FIGURE V. DISCIPLINES EXCELLENCE ANALYSIS IN TERMS OF THE WORLD ESI RANKING FOR 90 WORLD WELL-KNOWN UNIVERSITIES (Source: THE-WUR 2014-2015 \& ESI database @2014-10)

In table 2, a new ranking is made to examine how various disciplines are rated within each university by paper citations. 8 universities are randomly selected from the set of world wellknown universities as addressed above. In City University of Hong Kong, there are 9 disciplines ranking top 1\% in the world ESI and engineering discipline and physics discipline perform better than other 7 disciplines in terms of paper citations.

TABLE II. RANKINGS OF PAPER CITATIONS FOR EACH DISCIPLINE IN SOME WORLD WELL-KNOWN UNIVERSITIES (SOURCE: THE-WUR 2014-2015 \& ESI DATABASE @2014-10)

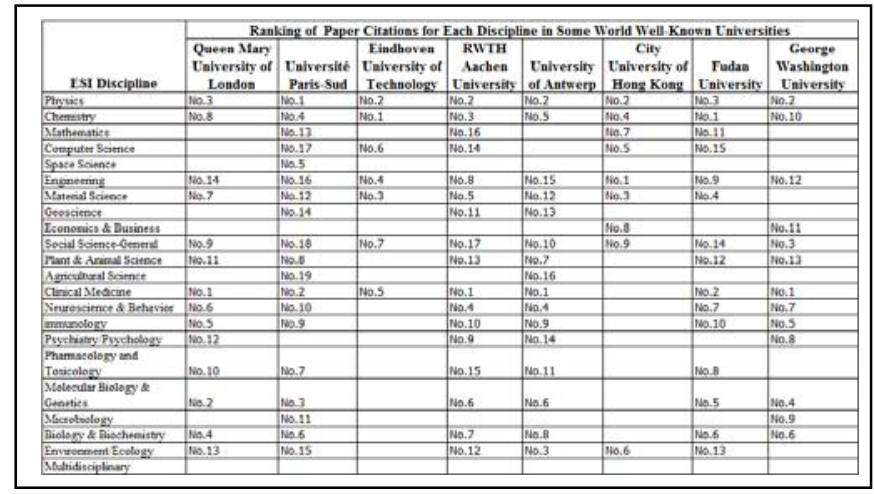

\section{China 985-project universities}

Project 985 in China is a project to promote the Chinese higher education system by fostering world-class universities in the 21 st century. There are 39 985-project universities in China now, which represent the best of Chinese universities to many extents. In order to be clear about the discipline excellence of 985-project universities and the gap with world-class universities, the quantities of disciplines ranking top $1 \%$ in the world ESI of each university have been examined. The result is shown in table 3, which illustrates that only 5 Chinese universities, including Peking University, Zhejiang University, Shanghai Jiaotong University, Sun Yat-sen University and Fudan University, have the number specified not less than 15, equivalent to the average level of world well-known universities. Peking University has 19 disciplines ranking as top $1 \%$ in the world ESI, which achieves the average level of world first-class university. The gap between most of 985project universities and world-class universities are easily manifested in table 3 .

TABLE III. QUANTITY OF ESI DISCIPLINES RANKING TOP $1 \%$ IN THE WORLD ESI FOR 985-PROJECT UNIVERSITIES IN CHINA (SOURCE: THE WORLD UNIVERSITY RANKING 2014-2015 \& ESI DATABASE @2014-10)

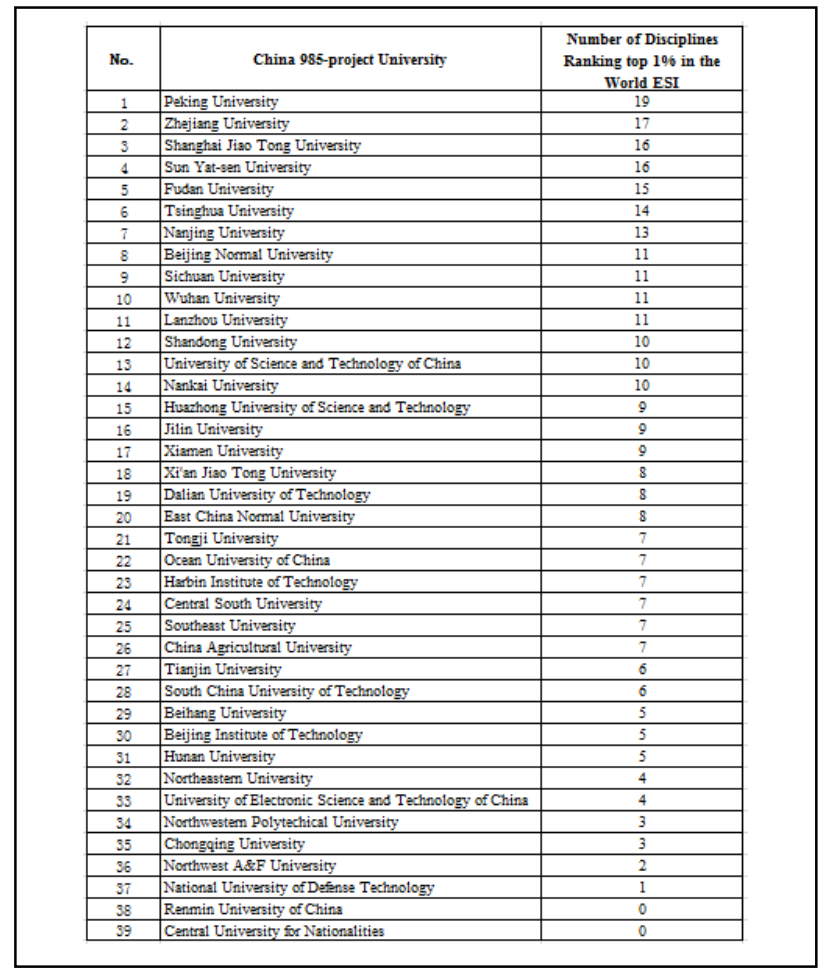

\section{CONCLUSIONS}

\section{A. Gap Existing between World-class Universities and} Chinese 985-project Universities in Discipline Excellece

It is a straightforward means to examine discipline excellence via investigating rankings of disciplines in the world ESI. According to analysis above, about half of world-class universities, saying including world first-class universities and world well-known universities as defined in this paper, have not less than 17 disciplines ranking top $1 \%$ in the world ESI. However, only a bit more than $5 \%$ of Chinese 985 -project universities is comparable to this level. The gap between these Chinese top-level universities and world-class universities remains significantly and also are further disclosed accordingly in Fig. 6. 


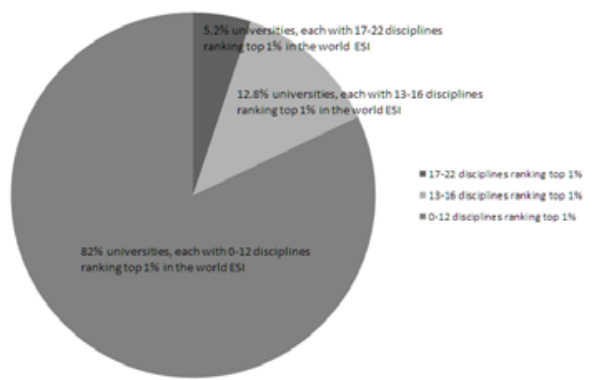

FIGURE VI. DISCIPLINES EXCELLENCE ANALYSIS IN TERMS OF THE WORLD ESI RANKING FOR 39 CHINESE 985PROJECT UNIVERSITIES (Source: ESI database @,2014-10)

\section{B. Discipline Profile of world-class universities}

According to the above analysis, world-class universities usually have excellent performance in disciplines, averagely, each having about 17 disciplines ranking top $1 \%$ in the world ESI, out of total 22 ESI disciplines. World-class universities often share certain commonalities of discipline profiles, generally demonstrating outstanding performance in medical domain and its relevant areas, having profound basis in physics, chemistry and mathematics domains, and showing great excellence in applied science domains including space science, computer science, and material science, etc. Such major patterns can be either pictured in Fig. 7 and named as Olive Type; or pictured in Fig. 8 and named as Dumbbell Type in this paper, depending on how well applied science performs over basic science within each university.

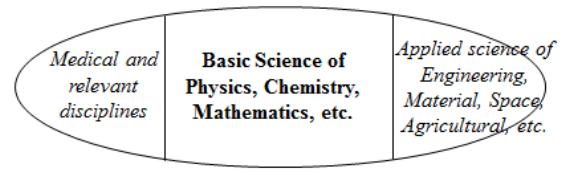

FIGURE VII OLIVE TYPE OF DISCIPLINE PROFILE FOR WORLD-CLASS UNIVERSITIES

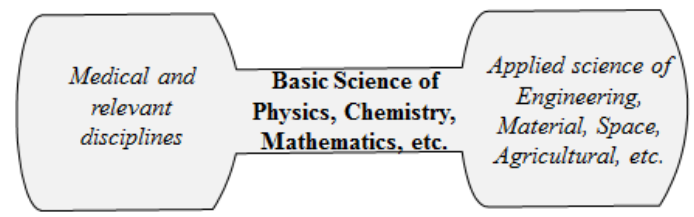

FIGURE VIII. DUMBBELL TYPE OF DISCIPLINE PROFILE FOR WORLD-CLASS UNIVERSITIES

\section{More Enlightenmens on Chinese universities}

Performance indicators should be used as aids or tools of management by universities. Finding and applying appropriate performance indicators are critical for modern universities, especially for universities in China, which are going through the transition phase driven by improving excellence. Thus, the final suggestions include (1) the gap between Chinese universities and world-class universities are well reflected in this paper, in terms of the quantity of disciplines ranking top $1 \%$ in the world ESI, it's meaningful to take ESI as a measurable and recognized performance indicator not only for evaluating university performance, but also for setting goals while Chinese universities are establishing world-class universities; (2) basic science is essential and indispensable for the discipline development of university. Given a strong support from basic science, Chinese universities can obtain rich nutrition for the further development of applied science, and promisingly keep a good balance between basic science and applied science [5].

\section{ACKNOWLEDGMENT}

On the completion of this paper, I would like to appreciate the sponsorship of Northwestern Polytechnical University 2013 Higher Education Research Funding Project - Research on Connotation and Strategy for the Internationalization of Higher Education (2013GJZ01).

\section{REFERENCES}

[1] Pat. Worgan, "Focus on Higher Education Performance Indicators in Higher Education," Management in Education,vol. 4, pp. 0892-0206, May 1990.

[2] Zheng Yan,Yang Jie, "Current Status and Development Trend of ESI World's Top $1 \%$ of Chinese Engineering Disciplines," Research in Higher Education of Engineering,vol. 6, pp. 35-39, 2014.

[3] Liu Hong, Xu Jia-ying, "International Influence Evaluation on Disciplines of Universities in Shanghai:A Bibliometric Analysis Based on InCites Database," Fudan Education Forum, vol. 12, No 4, pp. 29-34.

[4] Zhao Rongying,Wang Song,Chai Wen,Qiu Junping, "Evaluation and Analysis of Academic Competitiveness of the World-class University:2014-2015," Journal of Chongqing University(Social Science Edition, vol. 21, No.1, pp. 120-127, 2015.

[5] Yuan Yun, "Academic discipline and research development for World first-class and well-known universities and relevant study and analysis", Internal Research Report of Northwestern Polytechnical University, unpublished. 